Check for updates

Cite this: J. Mater. Chem. B, 2021, 9, 6092

DOI: 10.1039/d1tb90111g

rsc.li/materials-b

\section{Correction: A short PEG linker alters the in vivo pharmacokinetics of trastuzumab to yield high-contrast immuno-PET images}

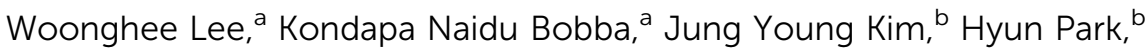 \\ Abhinav Bhise, ${ }^{a}$ Wanook Kim, ${ }^{a}$ Kiwoong Lee, ${ }^{a}$ Subramani Rajkumar, ${ }^{a}$ Bora Nam, ${ }^{a}$ \\ Kyo Chul Lee, ${ }^{b}$ Sang Hyuk Lee, ${ }^{c}$ Sanghwan Ko, de Hye Jin Lee, ${ }^{c}$ Sang Taek Jung ${ }^{\text {de }}$ \\ and Jeongsoo Yoo*a
}

Correction for 'A short PEG linker alters the in vivo pharmacokinetics of trastuzumab to yield highcontrast immuno-PET images' by Woonghee Lee et al., J. Mater. Chem. B, 2021, 9, 2993-2997, DOI: 10. 1039/D0TB02911D.

The authors of this article have noticed an error in the grant acceptance year of the Kyungpook National University Development Project Research Fund, in the acknowledgments section. The corrected acknowledgements should read as follows:

'This work was supported by the R\&D program through the National Research Foundation of Korea funded by the Ministry of Science, ICT \& Future Planning (No. 2019R1A2C2084313, 2020M2D8A3094031 and 2019H1D3A1A01102643). This research was partially supported by Kyungpook National University Development Project Research Fund, 2018. The Korea Basic Science Institute is acknowledged for MALDI-MS measurements.'

The Royal Society of Chemistry apologises for these errors and any consequent inconvenience to authors and readers.

\footnotetext{
${ }^{a}$ Department of Molecular Medicine, Brain Korea 21 four KNU Convergence Educational Program of Biomedical Sciences for Creative Future Talents, School of Medicine, Kyungpook National University, Daegu 41944, Republic of Korea. E-mail: yooj@knu.ac.kr

${ }^{b}$ Division of Applied RI, Korea Institute of Radiological and Medical Sciences, Seoul 01812, Republic of Korea

${ }^{c}$ Department of Chemistry and Green-Nano Materials Research Center, Kyungpook National University, 80 Daehakro, Buk-gu, Daegu, 41566, Republic of Korea

${ }^{d}$ BK21 Graduate Program, Department of Biomedical Sciences, Korea University College of Medicine, Seoul 02841, Republic of Korea

${ }^{e}$ Institute of Human Genetics, Korea University College of Medicine, Seoul 02841, Republic of Korea
} 